\title{
Coupled Nitric Oxide and Autonomic Receptor Functional Responses in the Normal and Inflamed Urinary Bladder of the Rat
}

\author{
R. VESELÁ ${ }^{1,2}$, H. ASKLUND ${ }^{2}$, P. ARONSSON ${ }^{2}$, M. JOHNSSON ${ }^{2}$, V. WSOL $^{1}$, \\ M. ANDERSSON ${ }^{2}$, G. TOBIN ${ }^{2}$ \\ ${ }^{1}$ Department of Biochemical Sciences, Faculty of Pharmacy, Charles University, Hradec Králové, \\ Czech Republic, ${ }^{2}$ Department of Pharmacology, Institute of Neuroscience and Physiology, \\ Sahlgrenska Academy at the University of Gothenburg, Gothenburg, Sweden
}

Received November 8, 2011

Accepted April 27, 2012

On-line June 6, 2012

\section{Summary}

Both divisions of the autonomic nervous system are involved in regulation of urinary bladder function. Several substances, other than noradrenaline and acetylcholine, seem to play important roles in physiology and pathophysiology of lower urinary tract. In the current study, we aimed to examine if there exist interplays between nitric oxide (NO) and autonomic transmitters and if such interactions vary in different parts of the urinary bladder in healthy and cyclophosphamide (CYP)-induced cystitic rats; when administered to the animals (100 mg/kg; i.p.), the cytotoxic CYP metabolite acrolein induces bladder inflammation. In the current study a series of in vitro functional studies were performed on detrusor muscle strip preparations. Stimulation with electrical field stimulation (EFS), methacholine, adenosine 5 '-triphosphate (ATP), and adrenaline evoked contractile responses in isolated bladder preparations that were significantly reduced in cyclophosphamide (CYP)-treated rats. While the nitric oxide synthase inhibitor $\mathrm{N}^{\omega}$-nitro-L-arginine (L-NNA; $10^{-4} \mathrm{M}$ ) did not affect contractile responses in normal, healthy strip preparations, it significantly increased the contractile responses to EFS, methacholine and adrenaline, but not to ATP, in the bladders from the CYP-treated rats. In the CYP-treated rats, the ATP-evoked relaxatory part of its dual response (an initial contraction followed by a relaxation) was 6-fold increased in comparison with that of normal preparations, whereas the isoprenaline relaxation was halved in the CYP-treated. While L-NNA $\left(10^{-4} \mathrm{M}\right)$ had no effect on the isoprenaline-evoked relaxations, it reduced the ATP-evoked relaxations in strip preparations from the bladder body of CYP-treated rats. Stimulation of $\beta_{2}$ - and $\beta_{3}$-adrenoceptors evoked relaxations and both responses were reduced in cystitis, the latter to a larger extent. In the trigone, the reduced ATP-evoked contractile response in the inflamed strips was increased by L-NNA, while L-NNA had no effect on the ATP-evoked relaxations, neither on the relaxations in healthy nor on the larger relaxations in the inflamed trigone. The study shows that both contractile and relaxatory functions are altered in the state of inflammation. The parasympathetic nerve-mediated contractions of the body of the bladder, evoked by the release of ATP and acetylcholine, were substantially reduced in cystitis. The relaxations to $\beta$-adrenoceptor and purinoceptor stimulation were also reduced but only the ATPevoked relaxation involved NO.

\section{Key words}

Nitric oxide - Inflammation • Urinary bladder • Autonomic transmitter • Rat

\section{Corresponding author}

R. Veselá, Department of Biochemical Sciences, Faculty of Pharmacy, Charles University, Heyrovského1203, CZ-50005 Hradec Králové, Czech Republic. E-mail: Renata.Vesela@ faf.cuni.cz

\section{Introduction}

The regulation of the urinary bladder function involves both divisions of the autonomic nervous system (Andersson et al. 2004, Giglio et al. 2009). While acetylcholine released from the parasympathetic innervation is the principal transmitter for the micturition contraction of the detrusor muscle, the sympathetic transmitter noradrenaline may exert relaxatory detrusor effects during the filling phase. The treatments of lower 
urinary tract disorders have mostly focused on the micturition phase. However, disturbances in the filling phase may indirectly induce urge and frequency (Andersson et al. 2003). $\beta$-adrenoceptor activation, as well as the release of nitric oxide (NO), have been suggested to participate in the smooth muscle relaxation that is a prerequisite for the bladder being able to receive and store urine.

Thus, in addition to the classical autonomic transmitters acetylcholine and noradrenaline, other autonomic transmitters participate in the micturition regulation as well. In many animals, and in humans during pathological conditions, purines contribute to the contractile and relaxatory responses (Palea et al. 1993, Shabbir et al. 2009). In addition, nitric oxide (NO) has been shown to play pivotal roles affecting the functional responses particularly in the inflamed urinary bladder, both in humans and in animals (Logadottir et al. 2004, Giglio et al. 2005). Interstitial cystitis is a chronic inflammatory bladder disease, characterized by urinary frequency, urgency and bladder/pelvic pain (Chancellor et al. 2004, Selo-Ojeme et al. 2004). Several substances besides NO, such as adenosine 5'-triphosphate (ATP), adenosine and prostanoids have been reported to be associated to the condition (Andersson 2002, Sun et al. 2006). In the rat urinary bladder, intraperitoneal injection of cyclophosphamide (CYP) induces cystitis and by that alterations of cholinergic contractile responses. CYP is metabolized through diethylcyclophosphamide to acrolein, a reactive and cytotoxic metabolite causing cystitis and thus being used as a model for IC (Cox 1979, Giglio et al. 2005, Batista et al. 2006). By blockade of the synthesis of NO, the cholinergic responses may be partially restored. Also, the removal of the urothelium abolishes the NO effects, showing the origin of the NO production (Andersson et al. 2008). Previous studies thus show a link between muscarinic receptor stimulation and NO release, which is particularly obvious in the inflamed urinary bladder of the rat (Giglio et al. 2005). Since NO has been reported to have both relaxatory and contractile effects on the urinary bladder, the impact of the increased production of $\mathrm{NO}$ on bladder function may be complex (Yanai et al. 2008). By cGMP-dependent mechanisms, NO causes relaxation, while a cGMP-independent mechanism, inducing the release of calcium, accelerates the spontaneous activity.

It has for some time been known that stimulation of $\beta$-adrenoceptors in the rat urinary bladder induces an increase of NO release (Birder et al. 2002). Regarding the
ATP-evoked relaxation, a small NO-dependent effect has been reported, but, likewise to that of $\beta$-adrenoceptor stimulation, it is unknown if this effect is influenced by inflammation (Khattab et al. 2007). In view of the NO significance in cystitis and of the changed cholinergic function of the bladder in CYP-induced cystitis (Giglio et al. 2007), we aimed to examine if there exist interplays between NO and other transmitters. That is, if noradrenaline and ATP induce NO effects, and if the effect appears only in the inflamed condition likewise to that of acetylcholine. Regarding the noradrenaline responses, we also aimed to characterize the specific $\beta$-adrenoceptor subtype involvement. We also aimed to examine if any such effect may vary in different parts of the urinary bladder. In order to induce experimental cystitis, rats were pre-treated with CYP.

\section{Methods and Materials}

The ethics committee at the University of Gothenburg approved the study design, in which 78 male rats (300-350 g) of the Sprague-Dawley strain were used. Cystitis was chemically induced by a single intraperitoneal injection of CYP $(100 \mathrm{mg} / \mathrm{kg})$, while controls received the same volume of saline $(9 \mathrm{mg} / \mathrm{ml} \mathrm{ip;} 1 \mathrm{ml} / \mathrm{kg})$. Both injections were conducted in the presence of the analgesic buprenorphinum (10 $\mu \mathrm{g} / \mathrm{kg}$ ip). Sixty hours subsequent to the saline/CYP treatment (at the peak of inflammation), the rats were anaesthetized with medetomidine (Domitor 0.3 $\mathrm{mg} / \mathrm{kg} \mathrm{im}$ ), then gassed and killed with an overdose of carbon dioxide. From the sacrificed rat, the urinary bladder was excised and prepared for functional examinations. Full thickness transverse strips were prepared $(6 * 2 \mathrm{~mm})$. Two strips were excised from the detrusor above ("bladder body strips") and one below ("trigonal strip") the orifices of the two ureters in accordance to a standard procedure (Tobin et al. 1995). The detrusor strip was mounted between two steel rods of which one was fixed and the other adjustable and connected to an isometric force transducer (Linton, Welwyn Garden City, UK). The strips were immersed in $25 \mathrm{ml}$ organ baths containing Krebs solution of the following composition (mM): $\mathrm{NaCl} 118, \mathrm{KCl} 4.6, \mathrm{CaCl}_{2}$ 1.25, $\mathrm{KH}_{2} \mathrm{PO}_{4} 1.15, \mathrm{MgSO}_{4} 1.15, \mathrm{NaHCO}_{3} 25$, and glucose 5.5 , and which was gassed with $5 \% \mathrm{CO}_{2}$ in $\mathrm{O}_{2}$ at $37^{\circ} \mathrm{C}$. The preparations were repeatedly stretched in order to obtain a stable tension of about $5 \mathrm{mN}$ after 45-60 min. Contractile (induced either by electrical field stimulation (EFS), by methacholine, by adrenaline or by ATP) and relaxatory (induced either by isoprenaline or ATP; dual 
response; a typical recording of an ATP response is shown in Figure 1) responses were used for the examination of NO functional effects. The non-selective NO synthase inhibitor $\mathrm{N}^{\omega}$-nitro-L-arginine (L-NNA) was used to block the synthesis of NO (Dubbin et al. 1990). In order to determine if inflammatory relaxatory changes are coupled to a specific subtype of $\beta$-adrenoceptor, the $\beta_{1-}$ and $\beta_{2}$-adrenoceptor antagonist propranolol and the " $\beta_{3}$-adrenoceptor antagonist" SR59230A (Mizuno et al. 2002) were employed. In the experimental protocol, EFS effects on the detrusor strip preparations were assessed at varying frequencies (between 1 and $60 \mathrm{~Hz}$ ) delivered at supramaximal voltage $(50 \mathrm{~V})$ as square wave pulses with a duration of $0.8 \mathrm{~ms}$. The EFS was delivered continuously until the peak response was obtained (stimulator: STM100C, Linton, Welwyn Garden City, UK). Data were recorded with the MP100WSW data acquisition system and Acquire software (Biopac, Goleta, CA, USA). All drugs were administered to the organ baths at a volume of $125 \mu$ l. A high $\mathrm{K}^{+}$solution (containing $124 \mathrm{mM} \mathrm{K}$ obtained by exchanging $\mathrm{Na}^{+}$for equimolar amounts of $\mathrm{K}^{+}$) was administered in the beginning of each experiment in order to assess the viability of each strip preparation. All drug concentrations presented in the Results section are based on pilot experiments, on previous studies or on literature data.

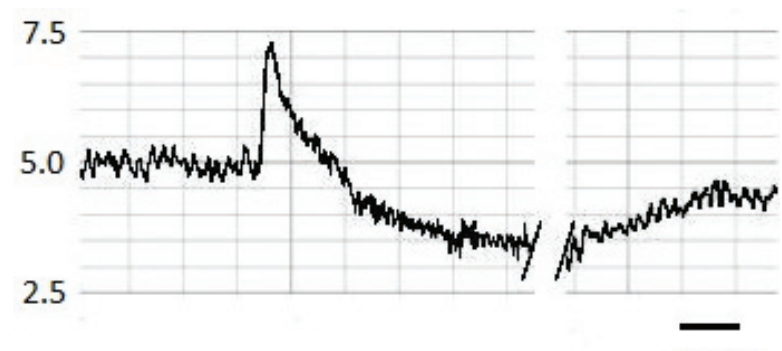

Fig. 1. Recording of an ATP $\left(10^{-3} \mathrm{M}\right)$ response. The fast contractile response is followed by a sustained relaxation (a middle $8 \mathrm{~min}$ part is omitted from the recording). The numbers indicate the muscle strip tension $(\mathrm{mN})$.

The following substances were employed in the functional experiments: adenosine 5'-triphosphate (ATP), $\mathrm{N}^{\omega}$-nitro-L-arginine (L-NNA), acetyl- $\beta$-methylcholine chloride (methacholine), isoprenaline hydrochloride, 3-(2-Ethylphenoxy)-1-[[(1S)-1,2,3,4-tetrahydronaphth-1yl]amino]-(2S)-2-propanol oxalate (SR59230A), adrenaline, propranolol hydrochloride and cyclophosphamide monohydrate. All drugs were purchased from Sigma-Aldrich, St Louis, MO, US.

\section{Statistics}

Statistical significance was determined by twoway analysis of variance or one-way analysis of variance (ANOVA) followed by the Bonferroni multiple comparison test. P-values of 0.05 or less were regarded as statistically significant. Data are presented as mean \pm S.E.M. Graphs were generated and parameters computed using the GraphPad Prism program (GraphPad Software Inc., San Diego, USA).

\section{Results}

Sixty hours after the intraperitoneal injection of $100 \mathrm{mg} / \mathrm{kg}$ of CYP, the macroscopical inspection of the urinary bladders showed obvious signs of inflammation. The signs included redness, bladder wall thickening, and vascularisation. No such observations were observed in the bladders of saline treated rats.

\section{Contractions}

Stimulation with EFS, methacholine, ATP and adrenaline evoked contractile responses in the bladders (Fig. 2 and Fig. 3). In the normal, healthy bladders the maximum responses to EFS $(40 \mathrm{~Hz})$, methacholine $\left(10^{-5} \mathrm{M}\right)$, ATP $\left(10^{-3} \mathrm{M}\right)$ and adrenaline $\left(10^{-4} \mathrm{M}\right)$ were $19.6 \pm 2.8 \quad(n=6), 23.8 \pm 2.6 \quad(n=6), 1.1 \pm 0.3 \quad(n=9)$, and $4.5 \pm 1.5(\mathrm{n}=9) \mathrm{mN}$, respectively. In the CYP-treated rat bladders, the contractile responses to either of the stimulations were significantly reduced. At EFS delivered at $40 \mathrm{~Hz}$, the contractile response was reduced by $64 \%$ ( $<<0.001$; Fig. 2), the response to methacholine at $10^{-5} \mathrm{M}$ by $50 \%(\mathrm{p}<0.001)$ and the responses to ATP $\left(10^{-3} \mathrm{M}\right)$ and adrenaline $\left(10^{-4} \mathrm{M}\right)$ by $75 \%$. While the examination of the nitric oxide synthase (NOS) inhibitor L-NNA $\left(10^{-4} \mathrm{M}\right)$ did not reveal any alteration of the contractile responses in normal, healthy strip preparations, its presence significantly increased the contractile responses to EFS, methacholine and adrenaline, but not to ATP, in the bladders from the CYP-treated rats (Fig. 4). While the blockade with L-NNA $\left(10^{-4} \mathrm{M}\right)$ only affected the EFS responses at $1 \mathrm{~Hz}$ (fourfold increase; $\mathrm{p}<0.01$; and tended to affect at $5 \mathrm{~Hz} ; 130 \%$ of basal response; ns; not shown), it normalized the response in the CYP-treated strips at large concentrations of methacholine $\left(10^{-5} \mathrm{M}\right)$. The same pattern regarding the effect of L-NNA appeared for the contractions to adrenaline in the inflamed strips as for methacholine (Fig. 4). 
a

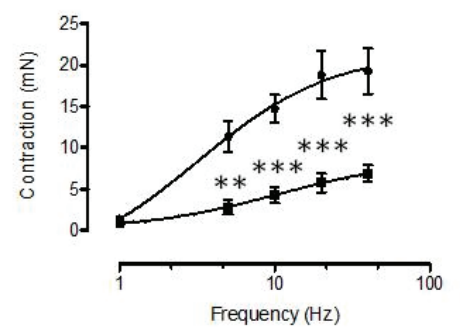

a
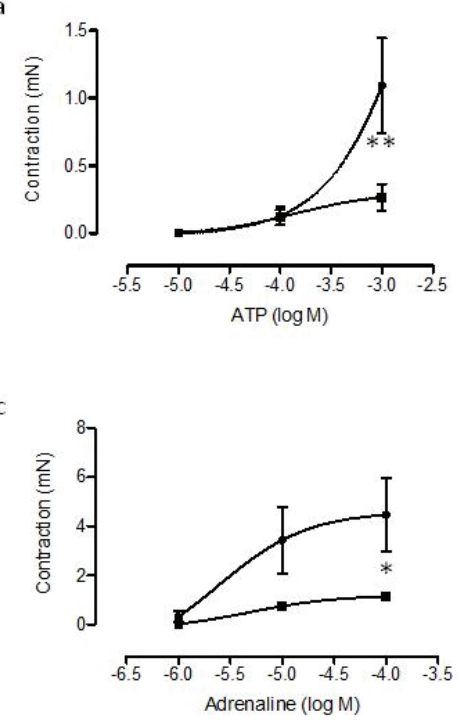

a
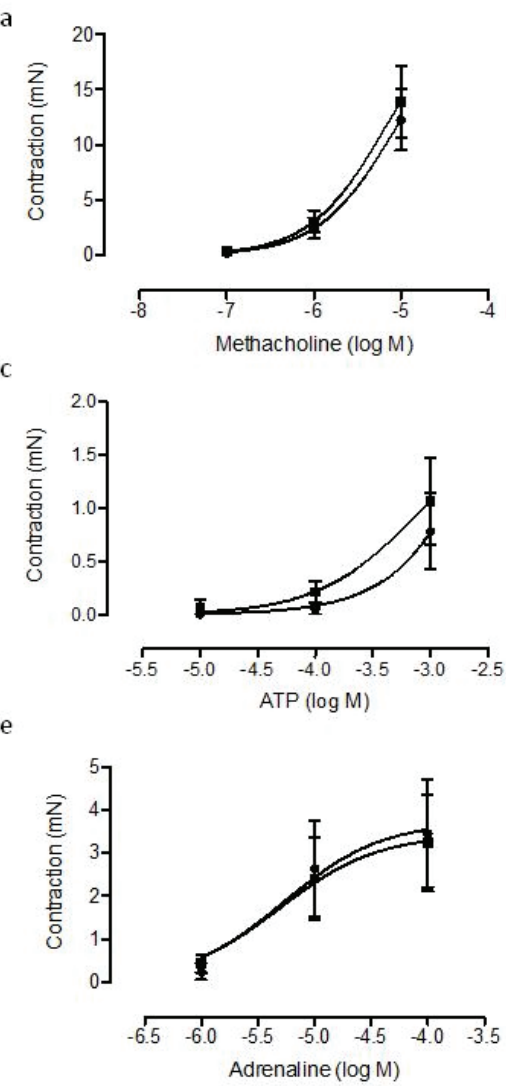

b

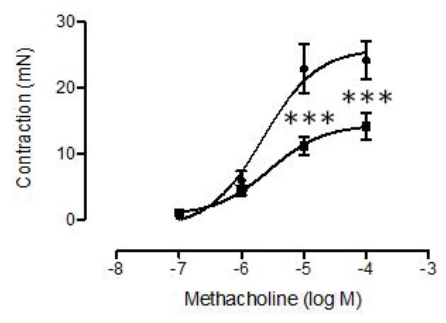

b

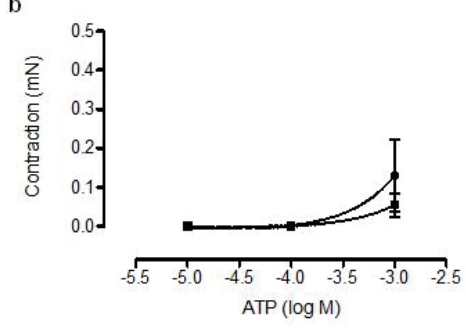

d



b

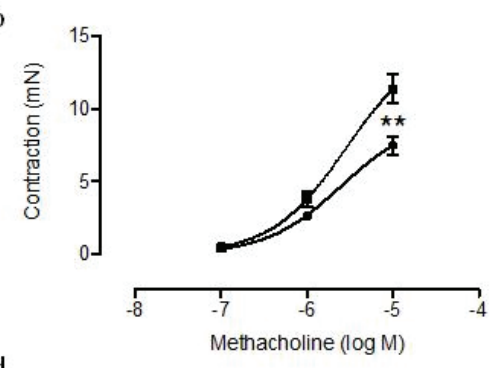

d
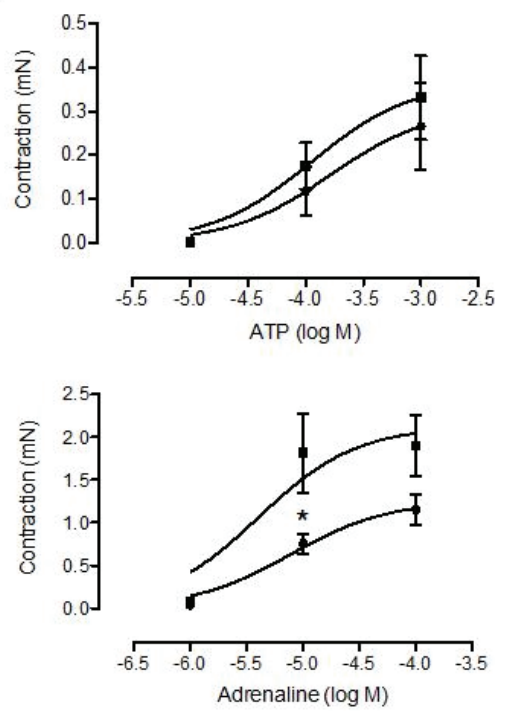

Fig. 2. Contractile responses to electrical field stimulation $(1-40 \mathrm{~Hz} ;$ a) and to methacholine (b) in (•) normal detrusor (bladder body) preparations $(n=6)$ and $(\boldsymbol{\square})$ inflamed detrusor (bladder body) preparations $(n=6)$. Vertical bars represent S.E.M. $* * \mathrm{p}<0.01, * * * \mathrm{p}<0.001$.

Fig. 3. Contractile responses to $\operatorname{ATP}(\mathbf{a}, \mathbf{b})$ and to adrenaline $(\mathbf{c}, \mathbf{d})$ in $(\bullet)$ normal preparations $(n=9)$ and $(\boldsymbol{\square})$ inflamed preparations $(n=9)$ of the bladder body ( $a$, c) and of the trigone (b, d). Vertical bars represent S.E.M. * $\mathrm{p}<0.05, * * \mathrm{p}<0.01$.
Fig. 4. Contractile responses to methacholine (a, b), ATP (c, d) and adrenaline (e, f) in normal bladder body preparations ( $\mathrm{a}, \mathrm{c}$ and $\mathrm{e}$ ) and inflamed bladder body preparations ( $b$, $d$ and $f$ ) before $(\bullet)(n=6)$ and after $(\boldsymbol{\square}) \quad(n=6)$ administration of L-NNA $\left(10^{-4} \mathrm{M}\right)$. Vertical bars represent S.E.M. * $\mathrm{p}<0.05, * * \mathrm{p}<0.01$. 

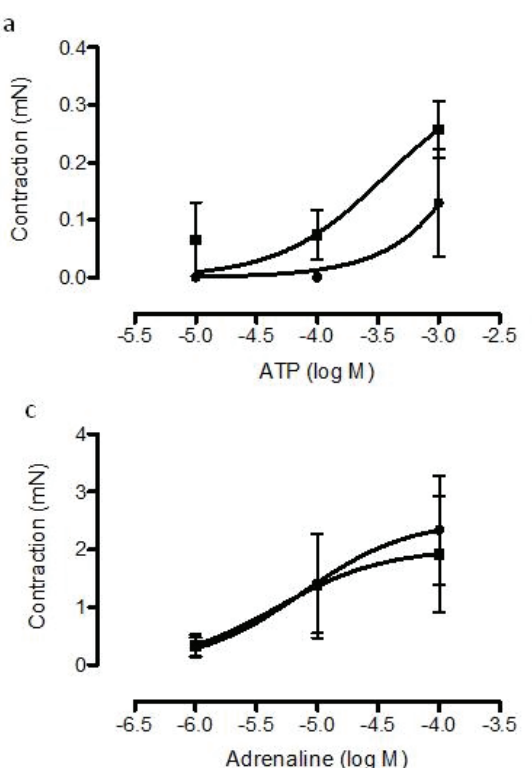

b

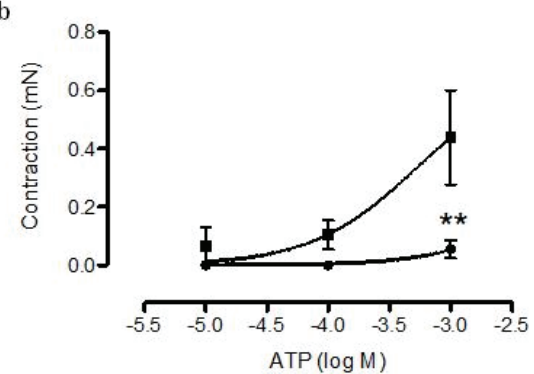

d

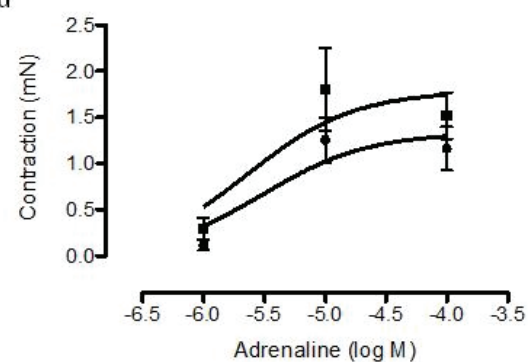

Fig. 5. Contractile responses to ATP $(\mathbf{a}, \mathbf{b})$ and adrenaline (c, d) in normal trigonal preparations $(\mathrm{a}, \mathrm{c})$ and inflamed trigonal preparations $(b, d)$ before $(\bullet)(n=9)$ and after $(\mathbf{\square})(n=9)$ administration of L-NNA $\left(10^{-4} \mathrm{M}\right)$. Vertical bars represent S.E.M. $* * \mathrm{p}<0.01$.
In the trigonal preparations, no statistically significant differences were observed between normal and inflamed preparations, even though the inflamed strips tended to respond less (Fig. 3). However, in contrast to the strip preparations from the bladder body, the ATP-evoked contractions, and only these of trigonal preparations from inflamed bladders, were significantly increased in the presence of L-NNA $\left(10^{-4} \mathrm{M}\right.$; Fig. 5).

\section{Relaxations}

ATP evoked a dual functional response in the rat urinary bladder; after the first and rapid contractile response, a sustained relaxation occurred. In normal bladders, the peak ATP relaxatory response was $-0.20 \pm 0.07 \mathrm{mN}\left(10^{-3} \mathrm{M} ; \mathrm{n}=9\right)$, while the corresponding relaxation to isoprenaline was $-2.0 \pm 0.2 \mathrm{mN}\left(10^{-5} \mathrm{M} ; \mathrm{n}=7\right.$; Fig. 6 and Fig. 7). In the bladder body preparations from CYP-treated rats, the ATP-evoked relaxation was sixfold increased, whereas the isoprenaline relaxation was halved. While L-NNA $\left(10^{-4} \mathrm{M}\right)$ had no effect on the isoprenaline-evoked relaxations, it reduced the ATP-evoked relaxations in strip preparations from the bladder body of CYP-treated rats.

In order to characterize the $\beta$-adrenoceptor subtype involved in the relaxatory response, two different antagonists were examined, propranolol $\left(\beta_{1,2}\right)$ and SR59230A $\left(\beta_{3}\right)$, on responses evoked by a standard concentration of isoprenaline $\left(10^{-5} \mathrm{M}\right)$ administered repeatedly in their absence and presence (Fig. 6). In the bladder body preparations the relaxations in the absence of propranolol were $-1.9 \pm 0.2$ (normal) and $-0.9 \pm 0.2$ (inflamed) $\mathrm{mN}$. In the groups to which SR59230A was administered the corresponding values were $-2.3 \pm 0.2$ and $-1.3 \pm 0.1 \mathrm{mN}$, respectively. The combination of the two almost abolished the responses to isoprenaline and the combined effect was of almost identical magnitude in normal and inflamed strips. When acting alone, propranolol inhibited about $60 \%$ of the isoprenalineevoked relaxation. The $\mathrm{IC}_{50}$ value for propranolol was significantly larger in the inflamed tissue than in the normal (6.50 \pm 0.33 vs 7.28 $\pm 0.14-\log M ; \mathrm{p}<0.05 ; \mathrm{n}=6$ and $\mathrm{n}=7$ ). Regarding the selective $\beta_{3}$-adrenoceptor antagonist SR59230A, the difference in antagonistic potency seemed to be even greater. In the normal preparations, the $\mathrm{IC}_{50}$ was $7.13 \pm 0.23-\log \mathrm{M}(\mathrm{n}=7)$, while it was $4.90 \pm 0.83$ $-\log \mathrm{M}(\mathrm{p}<0.01 ; \mathrm{n}=8)$ in the inflamed strip preparations.

In the trigonal preparations, ATP induced only small relaxatory effects in normal, healthy bladder preparations $(-0.07 \pm 0.06 \mathrm{mN} ; \mathrm{n}=10$; Fig. 7). In the inflamed preparations, this response was tenfold larger. No effect of NO was detected on the ATP-evoked trigonal relaxations. Isoprenaline, on the other hand, evoked trigonal relaxations of the same size in the normal and the inflamed bladders $(-1.1 \pm 0.2$ vs $-1.0 \pm 0.2 \mathrm{mN}$; $\mathrm{n}=6$ resp 7; not shown). Neither in strips of normal nor in strips of inflamed bladders did the NOS blockade $\left(\mathrm{L}-\mathrm{NNA} 10^{-4} \mathrm{M}\right)$ generate any observable alteration.

\section{Discussion}

This study confirms previous observations regarding the cholinergic responses in the normal and 


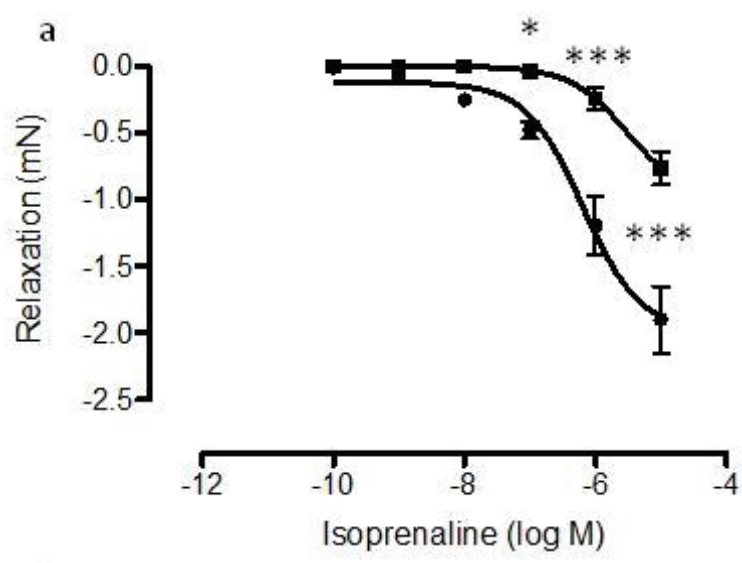

b
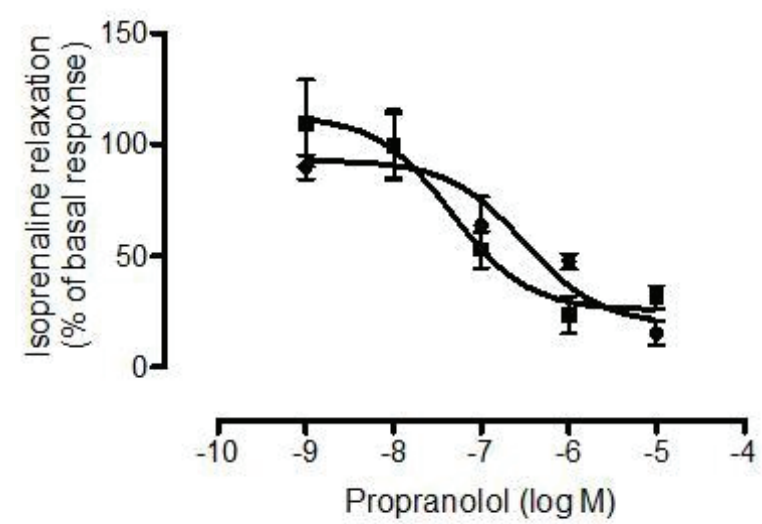

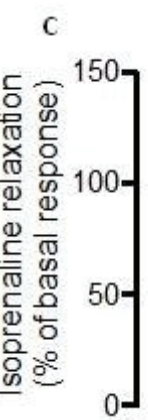

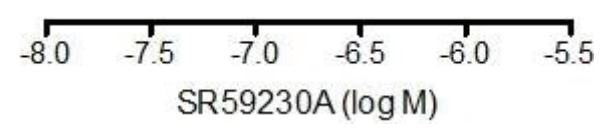

Fig. 6. Relaxatory responses to isoprenaline of bladder body preparations in normal $(\bullet)(n=7)$ and inflamed preparations $(\boldsymbol{\square})$ $(n=6)$. The upper panel shows the response to isoprenaline in absolute numbers. The lower panels show the effects of propranolol and SR59230A on a standard isoprenaline concentration $\left(10^{-5} \mathrm{M}\right)$. This concentration of isoprenaline was administered repeatedly, first in the absence and then in the presence of increasing concentrations of antagonist. The basal response was based on three consequtive isprenaline administrations in the absence of antagonist (mean value set to $100 \%$ ). Vertical bars represent S.E.M. ${ }^{*} p<0.05, * * * p<0.001$.

inflamed urinary bladder of the rat. Namely, that the muscarinic contraction is reduced in CYP-treated rats and that this reduction involves a NO-dependent part in addition to a general contractile capacity decrement of the smooth muscle (Giglio et al. 2005). The NO component in the cholinergic response is dependent on the concentration of the muscarinic receptor agonist and therefore seems unlikely to be an effect of a constitutive, basal release of NO. Furthermore, the NO anti-contractile effect appears only, or is at least more apparent, in the state of cystitis. Also, the NO effect in the cholinergic response disappears in urothelium-denuded bladders (Andersson et al. 2008). Tentatively, muscarinic receptors induce the release of urothelial NO that counteracts the contractile response. Regarding adrenergic stimulation, it is currently unknown whether or not there exists a similar link between adrenoceptors and NO. Conflicting reports occur, but if a link exists, it is minute (Theobald 1996, Andersson 1999). Regarding ATP, a small NO-dependent effect has been reported, however not described in cystitis (Khattab et al. 2007). Furthermore, since NO is a potent relaxatory agent of smooth muscles, it may very well, in addition to affecting the detrusor contractile phase, affect the receptive phase of the bladder, and/or the continence contraction of the outlet regions.

A non-adrenergic, non-cholinergic (NANC) component exists in many species in the parasympathetic contractile response (Langley et al. 1895). Later, this NANC transmitter was shown to be ATP, which thus acts together with the classical parasympathetic transmitter acetylcholine (Burnstock et al. 1972, Husted et al. 1980). Even though the NANC response is minute in healthy humans, it seems to grow in significance during pathological conditions (Palea et al. 1995). However, ATP evokes a dual response in the rat urinary bladder (McMurray et al. 1998). The transient contraction is followed by a sustained relaxation. While the contraction is mediated by $\mathrm{P} 2 \mathrm{X}(\mathrm{P} 2 \mathrm{X} 1)$ purinoceptors, the relaxation is mediated by $\mathrm{P} 1$ (A1, A2B) and possibly P2Y (P2Y2, 4 and 6) purinoceptors (Aronsson et al. 2010, Vesela et al. 2011). This means that a substantial part of the relaxation depends on the breakdown of ATP to adenosine.

Regarding the ATP evoked contraction this was, likewise to the cholinergic response, significantly reduced in the inflamed bladder. However, in contrast to the cholinergic response in the bladder body, it was not affected by the blockade of NOS neither in normal nor in inflamed strips. In the trigonal preparations, a NO contribution to the purinergic response was observed in the inflamed tissues. In contrast, the adrenergic 
contractile effects of the trigonum did not involve any NO components. However, adrenaline had some NO coupled effects in the bladder body. Thus, the involvement of $\mathrm{NO}$ in the responses varied depending on the agonist evoking the contraction, further underlining the hypothesis that the effects of NO cannot be caused by a constitutive production of NO but is released upon a specific stimulation.


b

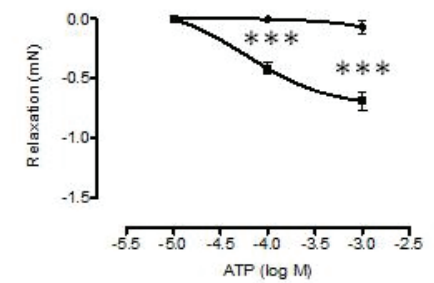

d

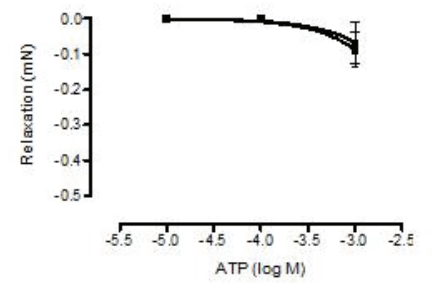

f
Fig. 7. Relaxatory responses to ATP. Upper panels show bladder body (a) and trigonal (b) responses in normal (•) $(n=9)$ and inflamed ( $\boldsymbol{\square}) \quad(n=9)$ preparations. Middle and lower row panels show normal $(\mathbf{c}, \mathbf{d})$ and inflamed preparations $(\mathbf{e}, \mathbf{f})$, respectively; the left column bladder body (c, e) and right column trigonal responses $(d, f)$. In the middle and lower row panels (c, d, e and f) show ATP responses before $(\bullet)(n=9)$ and after $(\boldsymbol{\nabla})(\mathrm{n}=9)$ administration of L-NNA $\left(10^{-4} \mathrm{M}\right)$. Vertical bars represent S.E.M. $* * \mathrm{p}<0.01 ; * * * \mathrm{p}<0.001$.
In the body of the inflamed bladder, a substantial, unspecific reduction of the contractility occurs that may affect all types of stimuli for contraction (Giglio et al. 2005). This was particularly obvious when the effects of EFS were studied. Here the responses were reduced by up to $70 \%$, which is consistent with previous observations (Giglio et al. 2007). Thus, the EFS contractile response suggests that a large part of the decrement of the contraction in inflammation occurs downstream to the receptor level. The part of the reduction in contractility in the bladders from CYP treated rats that is the result of an increased $\mathrm{NO}$ relaxatory effect was relatively small. However, at $1 \mathrm{~Hz}$, the blockade of NOS caused an increase of the contraction in inflamed strips by $300 \%$. This should be interpreted with caution, since a small increase from a low basal response gives large relative numbers.

Previous studies have shown that NO is not involved in adrenoceptor- or purinoceptor-evoked relaxations (Theobald 1996, Andersson 1999). However, non-neuronal NO has been suggested to contribute to the relaxation during the filling phase (Theobald 1996). Currently, it was wondered if the induction of inflammation might change this so that NO also gets involved in purinergic and adrenergic responses. Also, regarding the relaxations evoked by isoprenaline, a substantial decrement of the response occurred in the bladder body of the inflamed strips, but no change occurred in the inflamed trigonal preparations. For ATP, the alteration in the bladder body was the opposite to that of isoprenaline. Here, the ATP-evoked relaxation was enlarged in cystitis, which was the case in the trigonal part also. Regarding isoprenaline, the results confirm a previous occasional observation that the isoprenaline relaxation is reduced in cystitis (Giglio et al. 2007). In the current study, no effects were observed on the isoprenaline responses that could be caused by NO. For ATP, some part, however small, of the relaxation may be evoked by a purinoceptor-induced release of NO. Thus, we cannot confirm the observations made by Birder et al. (2002) on isolated urothelial cells. The reason for the discrepancy may be that the $\beta$-adrenoceptor-induced 
release of NO is not large enough to influence detrusor functional responses.

In the rat urinary bladder, as well as in the human urinary bladder, both $\beta_{2}$ and $\beta_{3}$ contribute to the adrenergic relaxation (Fujimura et al. 1999, Igawa et al. 1999). This was confirmed in the present results, in which antagonists at both subtypes had to be present for an almost total inhibition. Our results, however, may possibly indicate that the $\beta_{2}$-adrenoceptors contributed to a larger part than the $\beta_{3}$-adrenoceptors. In the examination of the $\beta$-adrenoceptor-evoked responses, it was wondered if any change by the CYP-treatment affected these responses, and further, if it affected both subtype responses equally. However, no NO-coupled effects could be observed on the $\beta$-adrenoceptor-evoked responses, and both the $\beta_{2^{-}}$and the $\beta_{3}$-adrenoceptor responses were altered by the CYP-treatment. According to the change of the $\mathrm{IC}_{50}$-values, the latter one was changed to a much larger extent. In future experiments, another design allowing for $\mathrm{pA}_{2}$ estimations need to be performed in order to confirm the present interpretation.

All in all, the present observations emphasizes that $\mathrm{NO}$ is a pivotal molecule for the inflammatory alterations in the rat urinary bladder (Logadottir et al. 2004). The symptoms of interstitial cystitis, which may seem to be the disease that the rat model shows most similarities with, include urge, frequency and pain. CYP induces a number of similar signs in rodents as in man (Wantuch et al. 2007). For the patient, the pain is often the prominent symptom, and this study does not indicate any possible targets for this symptom. On the other hand, urge and frequency are general symptoms of lower urinary tract disorders. Traditionally, in the development of pharmaceuticals for their treatments, focus has very much been at the expelling phase. Lately, the importance of the filling phase for the bladder function during the whole micturition cycle has been at attention (Andersson et al. 2003). However, since the inflammatory changes affected both the contractile and relaxatory functions by NO involvement, the molecule may have great impact on bladder function both by inhibiting the expelling phase and by affecting mechanisms in the filling phase.

\section{Conclusions}

The study shows that both contractile and relaxatory functions are altered in the state of inflammation. The parasympathetic nerve-evoked contraction, evoked by ATP and acetylcholine, of the body of the bladder is substantially reduced in cystitis. While the reduction of the muscarinic receptor response to some part depends on increases in the NO production, the reduction of the P2X-purinoceptor response does not. Inflammation does not induce any changes of the trigonal $\alpha$-adrenoceptor-mediated contractile responses as judged by the adrenaline contractile effects. The $\beta$-adrenoceptor relaxations of the bladder are reduced in cystitis, but they do not involve NO. Both $\beta_{2}$ and $\beta_{3}$-adrenoceptors cause relaxation of the bladder smooth muscle, and the latter receptor seems to be more affected by inflammation. The ATP-evoked relaxations are increased in cystitis, but only the purinergic response in the bladder body involves NO.

\section{Conflict of Interest}

There is no conflict of interest.

\section{Acknowledgements}

This study was supported by grants from Wilhelm och Martina Lundgrens Vetenskapsfond, by Charles University in Prague (Project SVV 263 004) and by Zentiva. We are indebted to Olga Arvidsson and Tayebeh Parsa for expert technical assistance.

\section{References}

ANDERSSON KE: Changes in bladder tone during filling: pharmacological aspects. Scand J Urol Nephrol Suppl 201: 67-72; discussion 76-99, 1999.

ANDERSSON KE: Overactive bladder-pharmacological aspects. Scand J Urol Nephrol Suppl: 72-81, 2002.

ANDERSSON KE, ARNER A: Urinary bladder contraction and relaxation: physiology and pathophysiology. Physiol Rev 84: 935-986, 2004.

ANDERSSON KE, YOSHIDA M: Antimuscarinics and the overactive detrusor - which is the main mechanism of action? Eur Urol 43: 1-5, 2003.

ANDERSSON MC, TOBIN G, GIGLIO D: Cholinergic nitric oxide release from the urinary bladder mucosa in cyclophosphamide-induced cystitis of the anaesthetized rat. Br J Pharmacol 153: 1438-1444, 2008. 
ARONSSON P, ANDERSSON M, ERICSSON T, GIGLIO D: Assessment and characterization of purinergic contractions and relaxations in the rat urinary bladder. Basic Clin Pharmacol Toxicol 107: 603-613, 2010.

BATISTA CK, BRITO GA, SOUZA ML, LEITAO BT, CUNHA FQ, RIBEIRO RA: A model of hemorrhagic cystitis induced with acrolein in mice. Braz J Med Biol Res 39: 1475-1481, 2006.

BIRDER LA, NEALEN ML, KISS S, DE GROAT WC, CATERINA MJ, WANG E, APODACA G, KANAI AJ: Betaadrenoceptor agonists stimulate endothelial nitric oxide synthase in rat urinary bladder urothelial cells. J Neurosci 22: 8063-8070, 2002.

BURNSTOCK G, DUMSDAY B, SMYTHE A: Atropine resistant excitation of the urinary bladder: the possibility of transmission via nerves releasing a purine nucleotide. Br J Pharmacol 44: 451-461, 1972.

CHANCELLOR MB, YOSHIMURA N: Treatment of interstitial cystitis. Urology 63 (Suppl 1): 85-92, 2004.

COX PJ: Cyclophosphamide cystitis - identification of acrolein as the causative agent. Biochem Pharmacol 28: 2045 2049, 1979.

DUBBIN PN, ZAMBETIS M, DUSTING GJ: Inhibition of endothelial nitric oxide biosynthesis by N-nitro-L-arginine. Clin Exp Pharmacol Physiol 17: 281-286, 1990.

FUJIMURA T, TAMURA K, TSUTSUMI T, YAMAMOTO T, NAKAMURA K, KOIBUCHI Y, KOBAYASHI M, YAMAGUCHI O: Expression and possible functional role of the beta3-adrenoceptor in human and rat detrusor muscle. J Urol 161: 680-685, 1999.

GIGLIO D, ARONSSON P, ERIKSSON L, TOBIN G: In vitro characterization of parasympathetic and sympathetic responses in cyclophosphamide-induced cystitis in the rat. Basic Clin Pharmacol Toxicol 100: 96-108, 2007.

GIGLIO D, RYBERG AT, TO K, DELBRO DS, TOBIN G: Altered muscarinic receptor subtype expression and functional responses in cyclophosphamide induced cystitis in rats. Auton Neurosci 122: 9-20, 2005.

GIGLIO D, TOBIN G: Muscarinic receptor subtypes in the lower urinary tract. Pharmacology 83: 259-269, 2009.

HUSTED S, SJOGREN C, ANDERSSON KE: Mechanisms of the responses to non-cholinergic, non-adrenergic nerve stimulation and to ATP in isolated rabbit urinary bladder: evidence for ADP evoked prostaglandin release. Acta Pharmacol Toxicol (Copenh) 47: 84-92, 1980.

IGAWA Y, YAMAZAKI Y, TAKEDA H, HAYAKAWA K, AKAHANE M, AJISAWA Y, YONEYAMA T, NISHIZAWA O, ANDERSSON KE: Functional and molecular biological evidence for a possible beta3adrenoceptor in the human detrusor muscle. Br J Pharmacol 126: 819-825, 1999.

KHATTAB MM, AL-HRASEN MN, EL-HADIYAH TM: Contractile activity of ATP and diadenosine tetraphosphate on urinary bladder in the rat: role of A1- and P2X-purinoceptors and nitric oxide. Auton Autacoid Pharmacol 27: 55-62, 2007.

LANGLEY JN, ANDERSON HK: The Innervation of the Pelvic and adjoining Viscera: Part II. The Bladder. Part III. The External Generative Organs. Part IV. The Internal Generative Organs. Part V. Position of the Nerve Cells on the Course of the Efferent Nerve Fibres. J Physiol 19: 71-139, 1895.

LOGADOTTIR YR, EHREN I, FALL M, WIKLUND NP, PEEKER R, HANNO PM: Intravesical nitric oxide production discriminates between classic and nonulcer interstitial cystitis. J Urol 171: 1148-1150; discussion 1150-1141, 2004.

MCMURRAY G, DASS N, BRADING AF: Purinoceptor subtypes mediating contraction and relaxation of marmoset urinary bladder smooth muscle. Br J Pharmacol 123: 1579-1586, 1998.

MIZUNO K, KANDA Y, KUROKI Y, NISHIO M, WATANABE Y: Stimulation of beta(3)-adrenoceptors causes phosphorylation of p38 mitogen-activated protein kinase via a stimulatory $G$ protein-dependent pathway in 3T3-L1 adipocytes. Br J Pharmacol 135: 951-960, 2002.

PALEA S, ARTIBANI W, OSTARDO E, TRIST DG, PIETRA C: Evidence for purinergic neurotransmission in human urinary bladder affected by interstitial cystitis. J Urol 150: 2007-2012, 1993.

PALEA S, PIETRA C, TRIST DG, ARTIBANI W, CALPISTA A, CORSI M: Evidence for the presence of both preand postjunctional P2-purinoceptor subtypes in human isolated urinary bladder. Br J Pharmacol 114: 35-40, 1995.

SELO-OJEME DO, ONWUDE JL: Interstitial cystitis. J Obstet Gynaecol 24: 216-225, 2004.

SHABBIR M, BURNSTOCK G: Purinergic receptor-mediated effects of adenosine 5'-triphosphate in urological malignant diseases. Int J Urol 16: 143-150, 2009. 
SUN Y, CHAI TC: Augmented extracellular ATP signaling in bladder urothelial cells from patients with interstitial cystitis. Am J Physiol Cell Physiol 290: C27-C34, 2006.

THEOBALD RJ JR: The effect of NG-monomethyl-L-arginine on bladder function. Eur J Pharmacol 311: 73-78, 1996.

TOBIN G, SJOGREN C: In vivo and in vitro effects of muscarinic receptor antagonists on contractions and release of $[3 \mathrm{H}]$ acetylcholine in the rabbit urinary bladder. Eur J Pharmacol 281: 1-8, 1995.

VESELA R, ARONSSON P, TOBIN G: Functional and morphological examinations of P1A1 purinoceptors in the normal and inflamed urinary bladder of the rat. Auton Neurosci 159: 26-31, 2011.

WANTUCH C, PIESLA M, LEVENTHAL L: Pharmacological validation of a model of cystitis pain in the mouse. Neurosci Lett 421: 250-252, 2007.

YANAI Y, HASHITANI H, HAYASE M, SASAKI S, SUZUKI H, KOHRI K: Role of nitric oxide/cyclic GMP pathway in regulating spontaneous excitations in detrusor smooth muscle of the guinea-pig bladder. Neurourol Urodyn 27: 446-453, 2008. 